\title{
ACL Injury Risk Factors Decrease \& Jumping Performance Improvement in Female Basketball Players: A Prospective Study
}

\author{
Benoit Pairot de Fontenay (Corresponding author) \\ Centre de Recherche et d'Innovation sur le Sport - CRIS - EA 647 \\ UFR STAPS - Université Claude Bernard - Lyon 1, 27-29, Bd du 11 Novembre 1918, 69622 Villeurbanne Cedex, France \\ E-mail: benoit.pdf@gmx.com \\ Telephone: (+33) 4724328 37, Fax: (+33) 472448010 \\ F. Lebon \\ Neurology Research Group, Centre for Brain Research, University of Auckland, Auckland, New Zealand \\ S. Champely \\ Centre de Recherche et d'Innovation sur le Sport - CRIS - EA 647 \\ UFR STAPS - Université Claude Bernard - Lyon 1, 27-29, Bd du 11 Novembre 1918, 69622 Villeurbanne Cedex, France \\ S. Argaud \\ Centre de Recherche et d'Innovation sur le Sport - CRIS - EA 647 \\ UFR STAPS - Université Claude Bernard - Lyon 1, 27-29, Bd du 11 Novembre 1918, 69622 Villeurbanne Cedex, France \\ Y. Blache \\ Centre de Recherche et d'Innovation sur le Sport - CRIS - EA 647 \\ UFR STAPS - Université Claude Bernard - Lyon 1, 27-29, Bd du 11 Novembre 1918, 69622 Villeurbanne Cedex, France \\ C. Collet \\ Centre de Recherche et d'Innovation sur le Sport - CRIS - EA 647 \\ UFR STAPS - Université Claude Bernard - Lyon 1, 27-29, Bd du 11 Novembre 1918, 69622 Villeurbanne Cedex, France \\ K. Monteil1 \\ Centre de Recherche et d'Innovation sur le Sport - CRIS - EA 647 \\ UFR STAPS - Université Claude Bernard - Lyon 1, 27-29, Bd du 11 Novembre 1918, 69622 Villeurbanne Cedex, France
}

Received: 18-06- 2013

doi:10.7575/aiac.ijkss.v.1n.2p.10
Accepted: 20-07- 2013

Published: 30-07- 2013

\begin{abstract}
The aim of this explorative study was to determine the most effective physical training program to reduce neuromuscular risk factors of Anterior Cruciate Ligament (ACL) tear and to improve jumping performance. Twentyfour female basketball players were divided into three groups: Specific Physical Training Group (SPTG), combined specific Physical and Mental Training Group (PMTG) and Control Group (CG). The training program was conducted over a period of eight weeks including two sessions per week during basketball practice. Dynamic valgus, Peak Vertical Impact Force (PVIF), Rate of Force Development (RFD), and jumping performance were measured at pre- and posttests. When all the participants were pooled, statistics showed a decrease $(-36 \%)$ in dynamic valgus. No significant results were observed for PVIF and RFD. Jumping performance improved by $12 \%$ in SPTG and remained constant in PMTG and CG. Adding specific physical training to basketball practice should be the most effective program to prevent ACL tear while improving jumping performance in young female basketball players.
\end{abstract}

Keywords: dynamic valgus; knee injury; motor imagery; performance

\section{Introduction}

In collective sports, training aims to improve players' physical, technical and tactical abilities while preserving physical integrity. However, this dual objective is rather difficult to achieve and seems contradictory. In basketball, velocity, 
strength and power are the most important physical qualities to develop (Cometti, 2002). These parameters can be evaluated by jumping performance, making the vertical jump test an appropriate measuring tool (Cometti, 2002).

Moreover, Basketball is a fast and aggressive sports with a high frequency of injuries (Meeuwisse, Sellmer, \& Hagel, 2003). ACL tears accounted for $8 \%$ of all game injuries for female basketball players (Agel et al., 2007) against $1.8 \%$ for male basketball players (Dick, Hertel, Agel, Grossman, \& Marshall, 2007) in the National Collegiate Athletic Association (NCAA). Moreover, the female-male ACL injury incidence ratio is greater than 3.5 in basketball (Arendt, Agel, \& Dick, 1999; Prodromos, Han, Rogowski, Joyce, \& Shi, 2007).

Anatomical, hormonal and neuromuscular factors were enumerated as internal risk factors to explain non-contact ACL tears in females (Pairot de Fontenay, 2009). On a neuromuscular level, three parameters contribute to lowered energy absorption in landing, increased ground reaction forces and risk of ACL injury (Hewett, Stroupe, Nance, \& Noyes, 1996): (1) a more erect posture (Decker, Torry, Wyland, Sterett, \& Richard Steadman, 2003); (2) a low activation of hamstrings and gluteus maximus muscles; and (3) the sur-activation of rectus femoris muscle (Zazulak et al., 2005). The poor dynamic control of the knee elicited high-risk positions, the most common being dynamic valgus which induced more strain on the ACL (Fukuda et al., 2003).

From these previous findings, specific training was developed to decrease neuromuscular risk factors and prevent ACL injury. Several studies confirmed that neuromuscular risk factors were reduced after training sessions. Hewett et al.(1996) observed a decrease in the peak knee landing abduction moment by $38 \%$. Irmisher et al.(2004) showed a decrease in Peak Vertical Impact Force (PVIF) by $26.4 \%$ and a reduction in the Rate of Force Development (RFD) by 27.3\% at landing. After Prevent injury Enhance Performance (PEP) program, Vescovi and Vanheest (2010) reported an improvement in sprint times but no effect on jumping performance, compared to their control group.

In the present study, a new perspective was to associate physical practice with Motor Imagery (MI). MI is an active process during which the representation of an action is mentally reproduced without any other output (Jeannerod, 1995). Mental practice is known to enhance motor learning (Driskell, Copper, \& Moran, 1994; Feltz \& Landers, 1983) and performance (Guillot \& Collet, 2008). MI may be an effective and inexpensive way to prevent ACL injury. As no motion is realized during the MI session, the training physical load is reduced. In addition, MI increases motor performance, as neurological adaptations after mental practice were shown to overlap those elicited by physical practice in the learning processes (Jackson, Lafleur, Malouin, Richards, \& Doyon, 2003). When combining mental and physical training, athletes were recently shown to produce greater lower limb strength gain than those only performing physical training combined with neutral cognitive tasks (Lebon, Collet, \& Guillot, 2010).

To our knowledge, no study has focused, during the same protocol, on the effects of different identified physical trainings. The purpose of this study is to assess the efficiency of two different physical training conditions on reducing neuromuscular risk factors of ACL tear while improving jumping performance in young female basketball players. A specific physical training and a combined physical and mental training were considered in this study. We hypothesized that, compared to a control group, the neuromuscular risk factors of ACL tear (dynamic valgus, PVIF and RFD) would decrease to a greater extent while jumping performance would increase more in both experimental groups.

\section{Materials and methods}

The study was non-randomized and took place during the pre-season. During an 8-weeks training period, three teams performed different trainings. Each team was allocated to a group: Specific Physical training Group (SPTG, n=9), combined Physical and Mental training Group (PMTG, $n=7$ ), and Control Group (CG, $n=8$ ). Biomechanical parameters were recorded while athletes performed a drop jump before and after the training-period. Four dependent variables were selected to test our assumptions: dynamic valgus, PVIF, RFD and flight time. Dynamic valgus was calculated to determine frontal loads on the knee, RFD and PVIF to assess the capacity to absorb energy and, flight times to evaluate jumping performance.

\subsection{Subjects}

Twenty-four young female basketball players (mean age: 15.5 years \pm 0.66 ), from three different clubs, volunteered to participate in this study. All participants played at a similar level, had at least two years of experience and reported no serious lower limb injury within the previous six months. As the participants were all under 18 years old, their parents signed an informed consent approved by the Ethical Committee of the University. As this study took place during the basketball playing pre-season, some athletes get transferred in another club and they have to be excluded from the tested sample. Therefore, statistics will be conducted on 18 subjects (SPTG, $n=8$; PMTG, $n=4$; and CG, $n=6$ ) and no significant difference was found between the groups in terms of height, weight and BMI.

\subsection{Training programs}

The three groups trained three times a week (six hours per week): CG only practice basketball, while SPTG practice basketball and underwent specific physical training and PMTG practice basketball and underwent specific physical and mental training. Physical training sessions of 20 minutes each took place twice a week as recommended in the literature (Mandelbaum et al., 2005; Myklebust et al., 2003; Olsen, Myklebust, Engebretsen, Holme, \& Bahr, 2005).

The format of the basketball practice, including tactical and technical training, was similar for each group.

For both SPTG and PMTG, information was given to athletes : (1) the functional role of ACL; (2) the movements that constraint the knee joint, the higher risk rate for female athletes; (3) the proper landing technique; and (4) the "knee over toe position" (Hewett, Lindenfeld, Riccobene, \& Noyes, 1999). To prevent ACL tear, the main goal was to reduce 
stress on the knee in all planes by correcting the wrong landing technique. The athletes learned the "knee over toe position" by keeping their knees on a same vertical line from hip to toe, in order to avoid dynamic valgus. They were also asked to perform "soft" landings to decrease PVIF (Laughlin et al., 2011). They were instructed to increase the flexion of hips and knees during landing, and to touch the ground with the forefoot first and roll back to the rearfoot in order to decrease anterior tibial shear force (Renstrom et al., 2008; Shimokochi, Ambegaonkar, Meyer, Lee, \& Shultz, 2012).

SPTG and PMTG included four sets of physical exercises: balance, plyometric, strengthening and core training (Appendix 1): (1) balance training was performed either directly on the floor or on a balance pad. The aim was to perform different single leg jumps in a row, to stabilize the last landing and to stay five seconds in the correct "knee over toe position" without losing balance; (2) high intensity plyometric exercises were performed to improve dynamic hip and knee stabilities as well as jumping performance (Markovic, 2007; Ziv \& Lidor, 2010) with the correct "knee over toe position"; (3) hamstrings muscle strengthening ("russian hamstrings exercise") and gluteus maximus muscle strengthening ("glute bridge") (Myer et al., 2009; Zazulak et al., 2005); and (4) core training to improve trunk proprioception and stability (Alentorn-Geli et al., 2009) with contraction of both abdominals and lower back muscles to stabilize the spine and the pelvis. Each week, the intensity of the sessions was increased by modifying the difficulty of the jump, the core training position, the number of repetitions, the training load and the resting time. Training sessions were performed before basketball practice to avoid neuromuscular fatigue and to improve integration of the new techniques (Renstrom et al., 2008).

During physical training, the duration of the exercises performed by PMTG were equally divided between physical and mental routine. Therefore, the physical training load was half as much as in SPTG. During mental practice, athletes were instructed to visualize and feel the movement they had just performed, i.e. they combined internal visual and kinesthetic imagery (Guillot \& Collet, 2008). To confirm that the participants were performing the mental exercises, they were requested to describe the nature of the mental images they were attempting to form. During this debriefing, they were asked to rate the degree of difficulty they encountered to accurately visualize the mental representation of the movement, using a 6-point Likert-type scale : $1=$ very easy to imagine/feel and 6=very difficult to imagine/feel (2, 3, 4 and 5 being intermediate levels).

\subsection{Drop jump test procedures}

A drop jump test was performed in the five days preceding and following the eight weeks training period. The test was carried out as described by Hewett et al., (2006). The athlete stood on a $43 \mathrm{~cm}$-height box, dropped down from the box onto a force platform (12 cm-height)(AMTI force plate, $1200 \mathrm{~Hz}$ ), adjacent to the box, then immediately performed a maximal vertical jump. The height of the drop down was $31 \mathrm{~cm}$ as described by Hewett et al., (2006) $(43-12=31 \mathrm{~cm})$. They were instructed to drop with both feet simultaneously, and to jump vertically as high as possible with arms up and both hands at the same level. Three attempts were performed barefoot, the best mark, defined as the best flight time, being kept for data processing. The tests were filmed with a video camera ((Ueye, IDS UI-2220SE-M-GL, 100Hz) placed in front of the subject.

\subsection{Data analysis}

From the video data, the angle between the vertical line and the tibial axis (middle of the line between medial and lateral malleolus and tibial tuberosity) in both legs was measured in the frontal plane (Figure 1). The difference between the angle in the starting position and the maximal angle during the plyometric phase corresponded to the dynamic valgus value. This is an easy-to-implement method to calculate dynamic valgus, while taking into account the anatomic valgus. The greater the angle, the greater the valgus. In order to study the reliability of this measurement (over the three attempts), the Intraclass Correlation Coefficient (ICC) using the model called $(2,1)$ by Shrout and Fleiss (1979) was calculated. The values in pre-test $(\mathrm{ICC}=0.84)$ and post-test $(\mathrm{ICC}=0.89)$, with low variability between groups, showed the reliability of this dynamic valgus measurement.

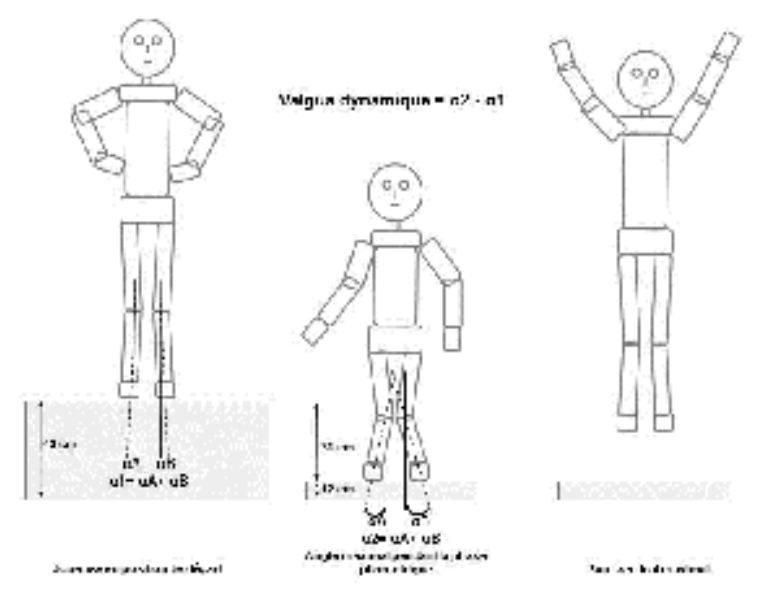

Figure 1. - Measurement of dynamic valgus after drop jump. 
PVIF corresponded to the maximum value of the vertical reaction force during the first landing. It was normalized to the subject body weight. RFD was calculated as a ratio between the normalized PVIF and the time taken to reach the peak (from the landing to the peak). This parameter determined the speed at which the stress on the knee increased.

\subsection{Statistical analyses}

Statistical analyses were conducted using the distribution free software R (R.2.7.2., R Foundation for Statistical Computing, Vienna, Austria) extended by the nlme and multcomp packages.

In the first part, descriptive statistics (mean and standard deviation) were computed by groups in each condition (preand post-test). Several recommendations (Wilkinson, 1999), editors or publication manual (APA, 2001) now encourage the report of effect sizes along with results of statistical tests for substantial significance. Moreover, the small size of the samples in this study and its consequences on the power of the hypotheses tested may hide the magnitude and the direction of effect of practical and clinical importance. Therefore, the Glass's $\Delta(\Delta=$ (MeanPost - MeanPre) / SDpre) was calculated for each group to evaluate a standardized mean change for a given parameter (Kline, 2004). It was compared to the conventional sizes $($ small $=0.2$, medium $=0.5$, large $=0.8)$ following the lines of Cohen $($ Cohen, 1988).

In the second part, a mixed repeated measures ANOVA was performed to assess two main effects and their interaction: group (between subjects) and condition (within subject). Post-hoc tests (Bonferroni) were then conducted using a general framework for multiple comparisons (Hothorn, Bretz, \& Westfall, 2008), adapted for repeated measurements. When the interaction was statistically significant, a two-step process was used: first, groups means evolution (pre/post) were simultaneously compared, secondly, these evolutions (pre/post) were simultaneously tested for nullity in the three groups. When the group effect but not the interaction was significant, Tukey's all-pair comparison of means was applied to better describe the main group. Statistical significance was accepted at p-value $<0.05$ level (after adjustment for multiple comparison).

\section{Results}

\subsection{Descriptive statistics}

Dynamic valgus, RFD, PVIF and flight time values at pre- and post-tests for the three groups were reported in Table I. The percentage of change (Delta) [mean (95\% CI)] and effect sizes (Glass's $\Delta$ ) were also noted in Table I.

Table I. - Pre-test and post-test data of dynamic valgus (rad), Rate of Force Development (RFD) (Bw/ms), Peak Vertical Impact Force (PVIF) (Bw), flight time (ms), percentage of change (Delta) [mean (95\% CI)] and effect sizes (Glass's $\Delta$ ) for the CG, SPTG and PMTG.

\begin{tabular}{cccccc}
\hline Data & Group & Pre-test & Post-test & $\begin{array}{c}\text { Delta } \\
\text { mean }(95 \% \text { CI) }\end{array}$ & $\begin{array}{c}\text { Effect size } \\
\text { Glass's } \Delta\end{array}$ \\
\hline \multirow{2}{*}{$\begin{array}{c}\text { Dynamic valgus } \\
\text { (rad) }\end{array}$} & SPTG & $0.30 \pm 0.18$ & $0.15 \pm 0.09$ & $-10(-36,15)$ & -0.79 \\
& PMT & $0.32 \pm 0.25$ & $0.24 \pm 0.10$ & $-5(-30,20)$ & -0.35 \\
& CP & $0.27 \pm 0.15$ & $0.18 \pm 0.13$ & $-6(-77,89)$ & -0.61 \\
RFD (Bw/ms) & PMTG & $0.09 \pm 0.06$ & $0.06 \pm 0.02$ & $3(-8,14)$ & 0.37 \\
& CG & $0.09 \pm 0.03$ & $0.14 \pm 0.07$ & $-8(-30,22)$ & -0.59 \\
& SPTG & $5.77 \pm 2.05$ & $5.37 \pm 1.54$ & $-1(-16,14)$ & 2.07 \\
PVIF (Bw) & PMTG & $4.67 \pm 1.75$ & $3.46 \pm 1.34$ & $-20(-24,-16)$ & -0.09 \\
& CG & $4.90 \pm 0.70$ & $5.62 \pm 1.40$ & $44(-15,103)$ & 2.88 \\
& SPTG & $409 \pm 44$ & $459 \pm 38$ & $9(2,16)$ & 1.15 \\
Flight time (ms) & PMTG & $466 \pm 25$ & $503 \pm 27$ & $5(2,8)$ & 1.53 \\
& CG & $461 \pm 44$ & $466 \pm 50$ & $1(-2,4)$ & 0.11 \\
\hline Bw = body weight & & & & &
\end{tabular}

\subsection{Test of significance}

Repeated measures ANOVA (groups * conditions) pointed out a main effect of condition for the dynamic valgus $(\mathrm{F}(1,12)=44.8 ; \mathrm{p}=0.003)$ but no interaction or main effect of group (all $\mathrm{p}>0.05)$. When all participants were pooled $(n=18)$, the amplitude of the dynamic valgus decreased $(-36 \%)$ from $0.30 \pm 0.05$ to $0.19 \pm 0.02$ rad during pre-test and post-test, respectively (Figure 2 and Table II). 


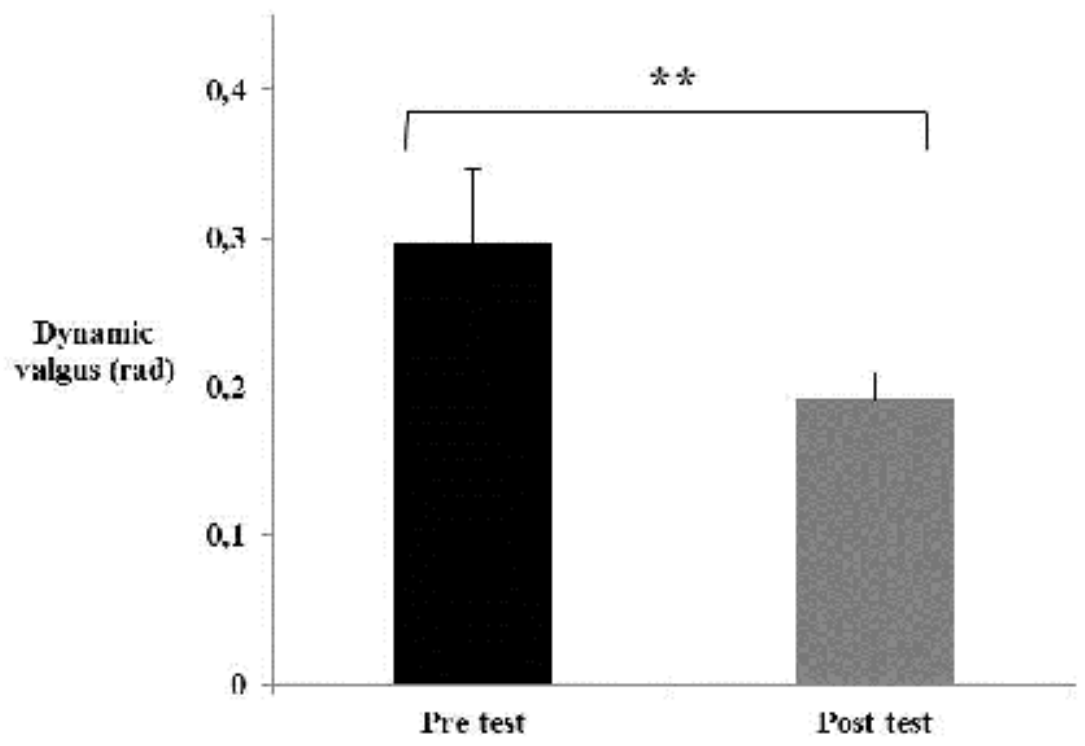

Figure 2. - Dynamic Valgus (rad) when all participants were pooled. $* * p<0.01$ for the condition effect.

No significant interaction, condition or group main effects were statistically significant with regards to the RFD and the PVIF (Table II).

Table II. - Results of the repeated measures ANOVA (group * condition): Dynamic valgus, Rate of Force Development (RFD), Peak Vertical Impact Force (PVIF) and flight time.

\begin{tabular}{cccc}
\hline Data & Interaction & Condition & Group \\
\hline Dynamic valgus & $\mathrm{p}=0.69$ & $\mathrm{p}<0.01$ & $\mathrm{p}=0.82$ \\
RFD & $\mathrm{p}=0.077$ & $\mathrm{p}=0.18$ & $\mathrm{p}=0.21$ \\
PVIF & $\mathrm{p}=0.32$ & $\mathrm{p}=0.50$ & $\mathrm{p}=0.49$ \\
Flight time & $\mathrm{p}<0.05$ & $\mathrm{p}<0.01$ & $\mathrm{p}=0.09$ \\
\hline
\end{tabular}

There was a significant interaction $(\mathrm{F}(2,16)=3.83 ; \mathrm{p}=0.044)$ for the flight time between pre-test and post-test. Posthoc tests showed a difference $(\mathrm{p}=0.016)$ between CG and SPTG (Figure 3 and Table II) with a significant increase in the flight time in SPTG (Figure 3).

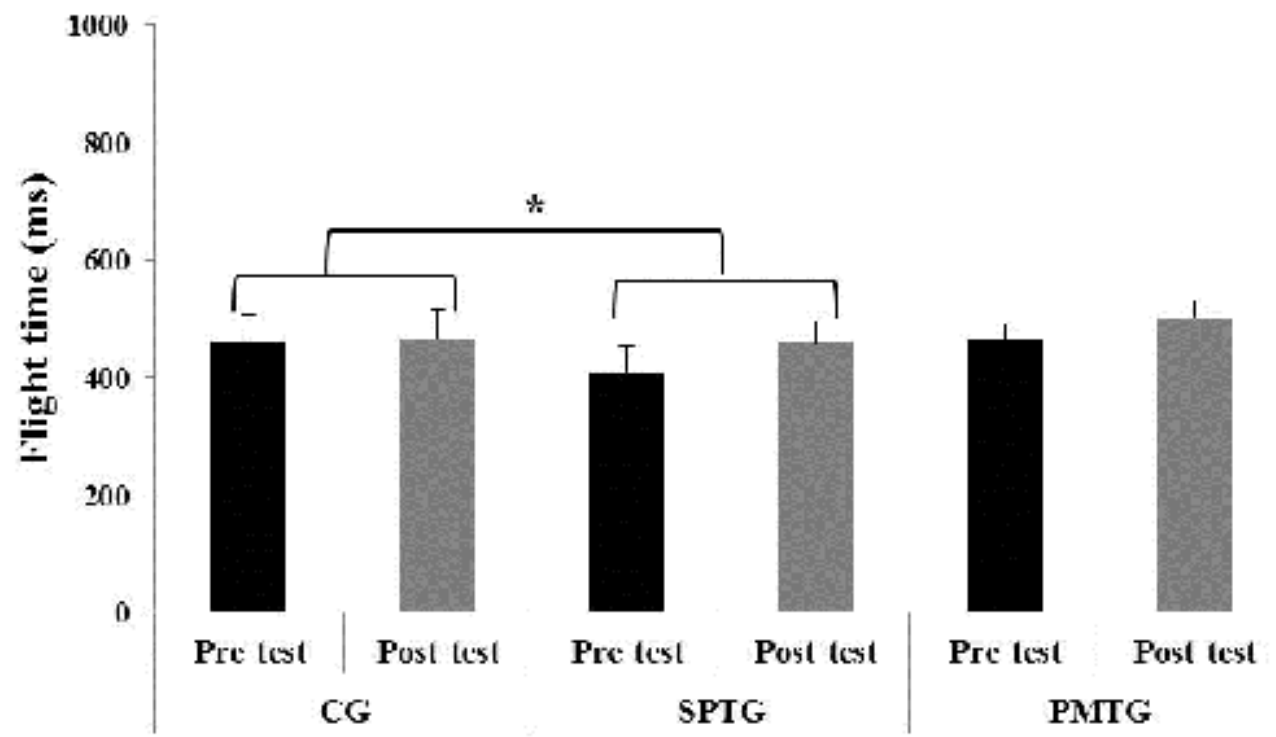

Figure 3. - Pre-test and post-test flight time values (ms) for CG, SPTG and PMTG. *p $<0.05$ for the post-hoc test. 


\section{Discussion}

This study aimed to assess the efficacy of two different physical training programs on the reduction of neuromuscular risk factors of ACL tear and the improvement of jumping performance in young female basketball players. This study is explorative in nature and its findings may be limited by the statistical significance of the results due to the relatively small number of participants. However, the trends which did emerged suggest that further research would be worthwhile.

\subsection{ACL injury risk factors}

The practice of basketball whether or not combined with physical training reduced the dynamic valgus by $36 \%$ after an 8 -week training period. This study was undertaken after the off-season break; therefore the return to sport could have led to a decrease in the dynamic valgus whatever the physical training. We could notice that from the effect sizes, the specific physical training seem to be more effective than the combined physical and mental training to decrease dynamic valgus. Hewett et al.(1996) found similar results following is work on specific preventive training. They observed a decrease of $38 \%$ in the peak knee landing abduction moment, corresponding to a decrease in the dynamic valgus (Renstrom et al., 2008). However, the authors did not specify when they performed the training in relation to the playing season, and there was no control group against which to compare the results. Some studies found opposite results and noted no change after training (Lephart et al., 2005; Pollard, Sigward, \& Powers, 2009). In the investigation of Lephart et al.(2005), the participants performed an isolated plyometric or basic resistance program without any practice planned, and the time of the year was not indicated. This difference in methodology could explain these different results.

The athletes who only practice basketball, with two large effect sizes, tended to increase RFD (+56\%) and PVIF $(+15 \%)$. During landing, the peak would be greater and reached earlier, and this could increase injury risks on the lower limb. These results slightly differed from the study of Irmischer et al.(2004), in which the authors showed no change of RFD and PVIF in the control group performing aerobic activity. Absent from this study however any details were regarding the content of the training.

Basketball practice and specific physical training had no incidence on the RFD or on the PVIF. These injury risk factors remained constant after the 8-weeks training period. Hewett et al.(1996) found a similar result for the PVIF, whereas Irmischer et al.(2004) showed a decrease of RFD by $27.3 \%$ in the tested group. In the latter, testing procedures differed. In the present study and Hewett et al.(Hewett et al., 1996), the participants were required to jump immediately after landing. In Irmischer et al.(2004), there was no jump following the landing from a $69 \mathrm{~cm}$-height box, and these differences could explain the discrepancy.

The results showed a tendency of the basketball practice and combined physical and mental training to decrease RFD and PVIF, with two medium effect sizes. The capacity to absorb energy at landing is likely to be enhanced as the players' techniques improve. In addition, the physical training load was half as much as in the specific physical training program. Indeed, during mental routine, no movement was performed, then, there was no stress on the knee joint.

Basketball practice alone was not sufficient to reduce the neuromuscular risk factors of ACL tear, whereas combining it with specific physical training would be effective. Moreover, adding physical and mental training to the practice decrease physical load during training session.

\subsection{Jumping performance}

Jumping performance was determined by the flight duration. Basketball practice did not improve jumping performance. By including specific physical training in the basketball practice, jumping performance increased $9 \%$. This result supported the findings of Hewett et al.(1996), who found an improvement of $9.2 \%$ of the jumping performance after 6 weeks of plyometric training. The improvement in jumping performance in both training programs was due to the high plyometric exercise load (Markovic, 2007; Ziv \& Lidor, 2010). However, Vescovi et al.(2010) found that there was no change in jumping performance following a specific training program. The lack of increase in the intensity of the plyometric exercises could explain this different result.

After including combined physical and mental training with basketball practice, there was a trend to a jumping performance improvement with a large effect size. These results support previous findings that showed an improvement in performance (Guillot \& Collet, 2008) or strength (Lebon et al., 2010) after mental training.

\subsection{Synthesis}

Basketball practice performed after the off-season break was not sufficient to decrease ACL injury risk factors and, contrary to our assumptions, it did not improve jumping performance in young female basketball players. Basketball practice and combined physical and mental training allowed a decrease in the physical training load. Due to the small sample size, more research is required to confirm that this training would be sufficient to reduce PVIF and RFD and to increase the jump height. Basketball practice and specific physical training seemed to be the best combination to improve jumping performance and to be the most effective to reduce ACL injury risk factors. Pollard et al.(2009) have demonstrated that an optimization of lower extremity mechanics lead to a decrease of the stress on the knee while increasing jump height. They also identified an increase in hip extensor activity, while knee extensors activity decreased in order to decelerate the body center of mass during landing.

The lack of statistical significance was due to the small size of the sample, potential effects of the different trainings on injury prevention and improvement of performance require further research to confirm our results. 


\section{Conclusion}

This study trended to demonstrate that, in the field of physical training, both injury prevention and performance improvement could be reached simultaneously. Basketball practice only was not sufficient to achieve this dual objective. Indeed, the integration of a specific physical training should be required to reduce the risk factors of ACL injury while increasing the performance of jump.

This study also highlighted the interest of using motor imagery in physical training programs. Coaches and physical trainers may be encouraged to apply this way of training based on the reduction of physical training loads. It was obviously relevant to preserve the physical integrity of the athletes while improving their performance.

\section{Acknowledgments:}

The authors express their thanks to the FFBB and Dr. Guincestre, for their financial support. We also thank directors, coaches and players from the three basketball clubs: US Laveyron, Elan Sportif Muzolais, and ASVBF.

\section{References}

Agel, J., Olson, D. E., Dick, R., Arendt, E. A., Marshall, S. W., \& Sikka, R. S. (2007). Descriptive epidemiology of collegiate women's basketball injuries: National Collegiate Athletic Association Injury Surveillance System, 1988-1989 through 2003-2004. J Athl Train, 42(2), 202-210.

Alentorn-Geli, E., Myer, G. D., Silvers, H. J., Samitier, G., Romero, D., Lazaro-Haro, C., et al. (2009). Prevention of non-contact anterior cruciate ligament injuries in soccer players. Part 1: Mechanisms of injury and underlying risk factors. Knee Surg Sports Traumatol Arthrosc, 17(7), 705-729.

APA. (2001). Manual of the American Psychological Association. Washington, DC: American Psychological Association.

Arendt, E. A., Agel, J., \& Dick, R. (1999). Anterior Cruciate Ligament Injury Patterns Among Collegiate Men and Women. J Athl Train, 34(2), 86-92.

Cohen, J. (1988). Statistical Power Analysis for the Behavioral Sciences. New Jersey: Lawrence Erlbaum Associates.

Cometti, G. (2002). La préparation physique en Basket. Paris: Chiron Editeur.

Decker, M. J., Torry, M. R., Wyland, D. J., Sterett, W. I., \& Richard Steadman, J. (2003). Gender differences in lower extremity kinematics, kinetics and energy absorption during landing. Clin Biomech (Bristol, Avon), 18(7), 662-669.

Dick, R., Hertel, J., Agel, J., Grossman, J., \& Marshall, S. W. (2007). Descriptive epidemiology of collegiate men's basketball injuries: National Collegiate Athletic Association Injury Surveillance System, 1988-1989 through 20032004. J Athl Train, 42(2), 194-201.

Driskell, J., Copper, C., \& Moran, A. (1994). Does mental practice enhance performance? J Appl Sport Psychol(79), 481-491.

Feltz, D., \& Landers, D. (1983). The effects of mental practice on motor skill learning and performance: A metaanalysis. J Sports Psychol (5), 25-27.

Fukuda, Y., Woo, S. L., Loh, J. C., Tsuda, E., Tang, P., McMahon, P. J., et al. (2003). A quantitative analysis of valgus torque on the ACL: a human cadaveric study. J Orthop Res, 21(6), 1107-1112.

Guillot, A., \& Collet, C. (2008). Construction of the motor imagery integrative model in sport: a review and theoretical investigation of motor imagery use. Int Rev Sport Exerc Psychol, 1, 31-44.

Hewett, T. E., Lindenfeld, T. N., Riccobene, J. V., \& Noyes, F. R. (1999). The effect of neuromuscular training on the incidence of knee injury in female athletes. A prospective study. Am J Sports Med, 27(6), 699-706.

Hewett, T. E., Myer, G. D., Ford, K. R., \& Slauterbeck, J. R. (2006). Preparticipation physical examination using a box drop vertical jump test in young athletes: the effects of puberty and sex. Clin J Sport Med, 16(4), 298-304.

Hewett, T. E., Stroupe, A. L., Nance, T. A., \& Noyes, F. R. (1996). Plyometric training in female athletes. Decreased impact forces and increased hamstring torques. Am J Sports Med, 24(6), 765-773.

Hothorn, T., Bretz, F., \& Westfall, P. (2008). Simultaneous inference in general parametric models. Biom J, 50(3), 346363.

Irmischer, B. S., Harris, C., Pfeiffer, R. P., DeBeliso, M. A., Adams, K. J., \& Shea, K. G. (2004). Effects of a knee ligament injury prevention exercise program on impact forces in women. J Strength Cond Res, 18(4), 703-707.

Jackson, P. L., Lafleur, M. F., Malouin, F., Richards, C. L., \& Doyon, J. (2003). Functional cerebral reorganization following motor sequence learning through mental practice with motor imagery. Neuroimage, 20(2), 1171-1180.

Jeannerod, M. (1995). Mental imagery in the motor context. Neuropsychologia, 33(11), 1419-1432.

Kline, R., B. (2004). Beyond Significance Testing: Reforming Data Analysis Methods in Behavioral Research. Washington, DC: American Psychological Association.

Laughlin, W. A., Weinhandl, J. T., Kernozek, T. W., Cobb, S. C., Keenan, K. G., \& O'Connor, K. M. (2011). The effects of single-leg landing technique on ACL loading. J Biomech, 44(10), 1845-1851. 
Lebon, F., Collet, C., \& Guillot, A. (2010). Benefits of motor imagery training on muscle strength. J Strength Cond Res, 24(6), 1680-1687.

Lephart, S. M., Abt, J. P., Ferris, C. M., Sell, T. C., Nagai, T., Myers, J. B., et al. (2005). Neuromuscular and biomechanical characteristic changes in high school athletes: a plyometric versus basic resistance program. Br J Sports Med, 39(12), 932-938.

Mandelbaum, B. R., Silvers, H. J., Watanabe, D. S., Knarr, J. F., Thomas, S. D., Griffin, L. Y., et al. (2005). Effectiveness of a neuromuscular and proprioceptive training program in preventing anterior cruciate ligament injuries in female athletes: 2-year follow-up. Am J Sports Med, 33(7), 1003-1010.

Markovic, G. (2007). Does plyometric training improve vertical jump height? A meta-analytical review. Br J Sports Med, 41(6), 349-355; discussion 355.

Meeuwisse, W. H., Sellmer, R., \& Hagel, B. E. (2003). Rates and risks of injury during intercollegiate basketball. Am $J$ Sports Med, 31(3), 379-385.

Myer, G. D., Ford, K. R., Barber Foss, K. D., Liu, C., Nick, T. G., \& Hewett, T. E. (2009). The relationship of hamstrings and quadriceps strength to anterior cruciate ligament injury in female athletes. Clin J Sport Med, 19(1), 3-8.

Myklebust, G., Engebretsen, L., Braekken, I. H., Skjolberg, A., Olsen, O. E., \& Bahr, R. (2003). Prevention of noncontact anterior cruciate ligament injuries in female team handball players : a prospective intervention study over three seasons. Clin J Sport Med, 13, 71-78.

Olsen, O. E., Myklebust, G., Engebretsen, L., Holme, I., \& Bahr, R. (2005). Exercises to prevent lower limb injuries in youth sports: cluster randomised controlled trial. $B M J, 330(7489), 449$.

Pairot de Fontenay, B., Argaud, S., Monteil, K. (2009). Rupture du LCA : Cas de l'athlète féminine. Journal de Traumatologie du Sport, 26, 155-162.

Pollard, C., D., Sigward, S., M., \& Powers, C., M. (2009, 27 august). Injury prevention training results in biomechanical changes consistent with decreased knee loading in females athletes during landing. Paper presented at the Annual Meeting of the American Society of Biomechanics, College Station, PA.

Prodromos, C. C., Han, Y., Rogowski, J., Joyce, B., \& Shi, K. (2007). A meta-analysis of the incidence of anterior cruciate ligament tears as a function of gender, sport, and a knee injury-reduction regimen. Arthroscopy, 23(12), 13201325 e1326.

Renstrom, P., Ljungqvist, A., Arendt, E., Beynnon, B., Fukubayashi, T., Garrett, W., et al. (2008). Non-contact ACL injuries in female athletes: an International Olympic Committee current concepts statement. Br J Sports Med, 42(6), 394-412.

Shimokochi, Y., Ambegaonkar, J. P., Meyer, E. G., Lee, S. Y., \& Shultz, S. J. (2012). Changing sagittal plane body position during single-leg landings influences the risk of non-contact anterior cruciate ligament injury. Knee Surg Sports Traumatol Arthrosc.

Shrout, P. E., \& Fleiss, J. L. (1979). Intraclass correlations: uses in assessing rater reliability. Psychol Bull, 86(2), 420428.

Vescovi, J. D., \& VanHeest, J. L. (2010). Effects of an anterior cruciate ligament injury prevention program on performance in adolescent female soccer players. Scand J Med Sci Sports, 20(3), 394-402.

Wilkinson, L. (1999). Statistical Methods in Psychology Journals: Guidelines and Explanations. American Psychologist, 54(8), 694-604.

Zazulak, B. T., Ponce, P. L., Straub, S. J., Medvecky, M. J., Avedisian, L., \& Hewett, T. E. (2005). Gender comparison of hip muscle activity during single-leg landing. J Orthop Sports Phys Ther, 35(5), 292-299.

Ziv, G., \& Lidor, R. (2010). Vertical jump in female and male volleyball players: a review of observational and experimental studies. Scand J Med Sci Sports. 
APPENDIX

Appendix 1: Composition of the specific preventive training program. Physical trainings were performed twice a week before basketball practice. The specific physical training group experienced only physical rehearsals while the combined specific physical and mental training group performed half physical and half mental practice.

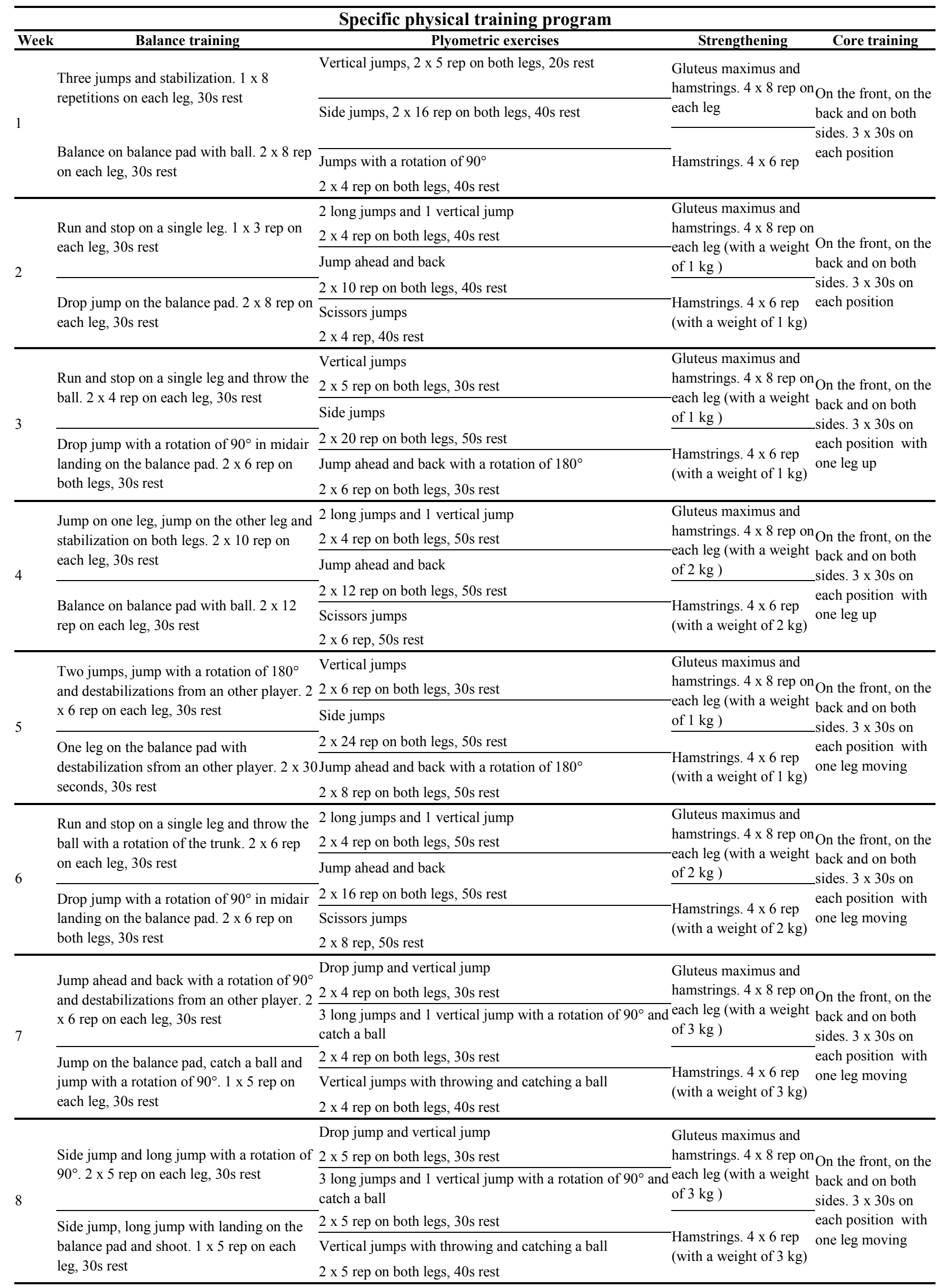

